\title{
GLAZBENE PREFERENCIJE UČENIKA PREMA NARODNOJ GLAZBI
}

\author{
Snježana Dobrota ${ }^{1}$, Matea Maslov ${ }^{2}$ \\ ${ }^{1}$ Odsjek za učiteljski studij, Filozofski fakultet, \\ Sveučilište u Splitu, Hrvatska; dobrota@ffst.hr \\ ${ }^{2}$ Omiš, Hrvatska; mateamaslov@yahoo.com
}

Primljeno: 2. 7. 2014.

\begin{abstract}
$U$ radu su istražene glazbene preferencije učenika četvrtih $i$ osmih razreda osnovne škole prema narodnoj glazbi. Izabrane su četiri varijable te je istražen njihov utjecaj na preferencije narodne glazbe. $U$ okviru istraživanja primijenjen je upitnik općih podataka te skala procjene za ispitivanje preferencija glazbenih ulomaka na uzorku od 157 učenika četvrtih i osmih razreda osnovne škole. Rezultati potvrđuju kako ne postoji statistički značajna razlika u preferencijama narodne glazbe učenika $i$ učenica, niti razlika u preferenciji narodne glazbe učenika četvrtih i osmih razreda. Rezultati također potvrđuju da učenici općenito više preferiraju vokalnu i vokalno-instrumentalnu narodnu glazbu u odnosu na instrumentalnu narodnu glazbu te da više preferiraju narodnu glazbu s područja Dalmacije u odnosu na narodnu glazbu iz drugih dijelova Hrvatske.
\end{abstract}

Ključne riječi: glazbene preferencije, narodna glazba, glazbena nastava

\section{Uvod*}

Istraživanja na području glazbe, psihologije i neuroznanosti otkrila su brojne čimbenike koji su uključeni u razvoj glazbenih preferencija (Juslin i Laukka, 2004; North i Hargreaves, 2008; Schwartz i Fouts, 2003). Glazba ima važnu ulogu u životu svakog čovjeka u njegovim

* Rad pod naslovom Glazbene preferencije učenika prema narodnoj glazbi diplomska je radnja obranjena 2014. godine na Filozofskom fakultetu Sveučilišta u Splitu, na Odsjeku za učiteljski studij, pod mentorstvom dr. sc. Snježane Dobrota. 
privatnim i društvenim aktivnostima, zato i ne čudi što se brojna istraživanja bave upravo ulogom glazbe u životu čovjeka (Colley, 2008). Zašto različiti ljudi vole različitu glazbu pitanje je na koje su pokušali odgovoriti brojni istraživači tijekom posljednjih desetljeća. Iako rezultati istraživanja potvrđuju kako na razvoj glazbenih preferencija utječu različiti faktori, nisu do kraja istraženi njihovi odnosi s glazbenim preferencijama pojedinca (Schäfer, 2008, 71-73).

Jedan od najpoznatijih teorijskih modela glazbenih preferencija, Interaktivna teorija glazbenih preferencija (The Interactive Theory of Music Preference, LeBlanc, 1981), nudi hijerarhijski organizirane razine varijabli koje su značajne za glazbene preferencije pojedinca, a uključuju značajke samog podražaja - glazbe, zatim fiziološke uvjete, afektivno stanje slušatelja i druge značajke poput osobina ličnosti, glazbene sposobnosti, etničke pripadnosti ili socioekonomskog statusa slušatelja. Hijerarhija varijabli koje utječu na glazbene preferencije sastoji se od osam razina kojima slušatelj obrađuje ulaznu informaciju. Najniže razine, od četvrte do osme, uključuju podražaj te kulturne i osobne čimbenike koji utječu na kretanje informacije do mozga slušatelja. Na višim razinama, od treće do prve, obrađuje se ulazna informacija i u skladu s tim slušatelj odgovara na podražaj. Dakle, varijable na najvišim razinama odgovor su na varijable utjecaja, odnosno na varijable nižih razina. Odgovor na najvišim razinama može biti odbacivanje podražaja, čime se završava proces, ili prihvaćanje podražaja, što dovodi do intenziviranja pozornosti prema ulaznim podacima.

Osma razina modela odnosi se na glazbu i okolinu, a sadržava devet varijabli koje utječu na ulaznu informaciju. Razine modela od sedme do treće govore o aktivnosti samog slušatelja. Na sedmoj, šestoj i petoj razini nalaze se tri varijable inhibicije koje »filtriraju« ulaznu informaciju. Na sedmoj razini to su fiziološki uvjeti, na šestoj osnovna pozornost, a na petoj razini afektivno stanje. Četvrta razina odnosi se na karakteristike slušatelja koje utječu na obrađivanje ulaznih podata$\mathrm{ka}$, a to su slušna osjetljivost, glazbena sposobnost, glazbena poduka, osobnost, spol, etnička pripadnost, socioekonomski status, sazrijevanje i pamćenje.

Treća razina modela označava početak faze slušateljeva djelovanja: na njoj se obrađuju podaci u slušateljevu mozgu. Druga razina sastoji se od četiriju varijabli (odluka o preferencijama, daljnja istraživanja podražaja i okoline, ponovljeno uzrokovanje, intenziviranje pozornosti) i 
na njoj se odlučuje o tome jesu li slušatelju potrebna dodatna iskustva kako bi formirao prosudbe. U slučaju potrebe dodatnih iskustava slušatelj se vraća na osmu razinu, a ako su prosudbe formirane, informacija nastavlja put do prve razine. Prva razina sastoji se od četiriju varijabli (odbacivanje, prihvaćanje, ponavljanje podražaja, intenziviranje pozornosti) te se tamo prihvaća ili se odbacuje (Dobrota, 2012, 45-47).

Drugi model glazbenih preferencija je Recipročni model glazbenog odgovora (The Reciprocal Response Model, Hargreaves, Miell i MacDonald, 2005). Autori modela pokušali su grupirati različite faktore koji utječu na glazbene preferencije, poput spola, dobi, osobnosti, glazbenih sposobnosti, glazbene poduke, socioekonomskog statusa, okoline i medija. Navedene faktore autori su grupirali u tri skupine - glazba, slušatelj i situacija u kojoj se slušatelj nalazi. Model je nazvan »recipročnim« zato što svaki od tri osnovna utjecaja ili čimbenika može istovremeno utjecati na ostala dva, a takvi su utjecaji dvosmjerni (North i Hargreaves, 2008, 123-126).

Iako navedeni modeli mogu poslužiti kao polazište u istraživanju glazbenih preferencija, oni imaju i svoje nedostatke, u prvom redu zato što ne donose odgovor na pitanje zašto ljudi uopće slušaju glazbu te zašto preferiraju određene glazbene stilove.

Postoji velik broj istraživanja koja se bave povezanošću različitih glazbeno-izražajnih sastavnica, poput tempa, dinamike, izvođača, ritma, melodije i ugođaja, s glazbenim preferencijama sudionika (LeBlanc, 1981; LeBlanc i McCrary, 1983; Flowers, 1988; Montgomery, 1996; Dobrota i Reić Ercegovac, 2009). Mali broj istraživanja bavio se preferencijama učenika prema narodnoj glazbi.

Na nastavi glazbene kulture pjeva se i sluša hrvatska narodna glazba. Učenici upoznaju vlastitu kulturu i razvijaju svijest o vlastitom kulturnom identitetu. Narodna glazba kod izvođača ili slušatelja često budi osjećaj pripadnosti obitelji, zajednici, narodu i kulturi. Prema tome, narodna glazba može potaknuti osjećaj identiteta temeljen na kulturi i glazbenoj baštini. U obrazovnom sustavu u kojem se koristi narodna glazba djeca su u stanju prepoznati vrijednost $i$ integritet njihove glazbene i kulturne tradicije.

Imajući u vidu važnost narodne glazbe u formiranju identiteta mladog čovjeka, u ovom ćemo istraživanju pokušati ispitati kakvi su stavovi učenika prema navedenom glazbenom stilu. 


\section{Cilj i problemi istraživanja}

Cilj istraživanja bio je istražiti glazbene preferencije učenika četvrtih i osmih razreda osnovne škole prema narodnoj glazbi te utjecaj spola i dobi na preferencije narodne glazbe. Također smo istražili postoje li razlike u preferencijama narodne glazbe s područja Dalmacije u odnosu na narodnu glazbu iz drugih dijelova Hrvatske te između instrumentalne i vokalne/vokalno-instrumentalne narodne glazbe.

U skladu s formuliranim ciljem postavljene su sljedeće hipoteze:

H1: Učenice u odnosu na učenike u većoj mjeri preferiraju narodnu glazbu.

H2: Učenici osmih razreda u odnosu na učenike četvrtih razreda $u$ većoj mjeri preferiraju narodnu glazbu.

H3: Učenici više preferiraju narodnu glazbu s područja Dalmacije u odnosu na narodnu glazbu iz drugih dijelova Hrvatske.

H4: Učenici više preferiraju vokalnu i vokalno-instrumentalnu narodnu glazbu u odnosu na instrumentalnu narodnu glazbu.

\subsection{Metoda}

\subsubsection{Sudionici}

Ispitivanje je provedeno u Omišu na uzorku od 157 učenika osnovne škole $(\check{Z}=89, M=68)$ četvrtih i osmih razreda (Tablica 1$)$. Istraživanje je provedeno u razdoblju od 27. veljače do 7. ožujka 2014. godine.

Tablica 1. Struktura uzorka $(\mathrm{N}=157)$

\begin{tabular}{|l|c|c|}
\hline Razred & Spol & N \\
\hline \multirow{2}{*}{ Četvrti } & $\mathrm{M}$ & 35 \\
\cline { 2 - 3 } & $\check{Z}$ & 45 \\
\hline \multirow{2}{*}{ Osmi } & $\mathrm{M}$ & 33 \\
\cline { 2 - 3 } & $\check{Z}$ & 44 \\
\hline Ukupno & & $\mathbf{1 5 7}$ \\
\hline
\end{tabular}




\subsubsection{Instrument $i$ postupak ispitivanja}

U istraživanju je korišten glazbeni nosač zvuka na kojemu se nalazilo deset glazbenih ulomaka narodnih pjesama, svaki u trajanju od oko jedne minute (Tablica 2). Glazbeni nosač zvuka konstruiran je isključivo za potrebe ovog istraživanja, a kriterij izbora glazbenih ulomaka bile su postavljene hipoteze (vokalna/vokalno-instrumentalna narodna glazba; narodna glazba Dalmacije/narodna glazba iz drugih dijelova Hrvatske). Za potrebe istraživanja konstruiran je upitnik (Prilog 1) koji se sastoji od dva dijela. Prvi dio upitnika sastavljen je od pitanja koja se odnose na spol, dob i upoznatost učenika s narodnom glazbom, a drugi dio je skala procjene sviđanja glazbe. Zadatak sudionika je bio da nakon odslušanog glazbenog ulomka na ljestvici Likertova tipa, zaokruživanjem brojeva od jedan do pet $(1=$ uopće mi se ne sviđa; $2=$ ne sviđa mi se; 3 $=$ osrednje mi se sviđa; $4=$ sviđa mi se; $5=$ jako mi se sviđa), procijene stupanj sviđanja pojedinog glazbenog ulomka.

Tablica 2. Glazbeni primjeri na nosaču zvuka

\begin{tabular}{|c|c|}
\hline $\begin{array}{l}\text { Područje iz kojeg } \\
\text { glazba potječe }\end{array}$ & Glazbeni primjer \\
\hline \multirow{5}{*}{$\begin{array}{l}\text { Glazbeni primjeri iz } \\
\text { Dalmacije }\end{array}$} & Trogirska kvadrilja, KUD »Kvadrilja«, Trogir \\
\hline & Letovanić, ansambl »Lado« \\
\hline & Diridonda, Starogrojčice \\
\hline & Monfrina (Splitski ples), KUD »Brodosplit«, Split \\
\hline & Paun leti, Klapa Sinj \\
\hline \multirow{5}{*}{$\begin{array}{l}\text { Glazbeni primjeri } \\
\text { iz drugih dijelova } \\
\text { Hrvatske }\end{array}$} & Poskakanac, KUD »Jasen«, Šaptinovci (Slavonija) \\
\hline & Igrajte nam, HKUD »Goričan« (Podravina) \\
\hline & Zginula je pikuša, KUD »Oštrc« (Međimurje) \\
\hline & Valcer, Božo Bernobić - Nadalin, Miloš Pernić (Istra) \\
\hline & Preko Drave (ulomak), Lidija Bajuk (Podravina) \\
\hline
\end{tabular}

Sudionicima je objašnjena svrha provođenja istraživanja, zajamčena im je anonimnost te su zamoljeni da iskreno i precizno odgovaraju na pitanja. Nakon ispunjavanja prvog dijela upitnika, sudionici su upućeni u način provođenja glazbenog dijela ispitivanja, odnosno u način provođenja procjene sviđanja glazbe pri čemu im nije rečeno o kojim se glazbenim ulomcima i izvođačima radi. 


\subsection{Rezultati i diskusija}

H1: Učenice u odnosu na učenike u većoj mjeri preferiraju narodnu glazbu.

Kako bismo testirali prvu hipotezu izračunat je t-test kojim se ispitalo utjecaj spola na preferencije narodne glazbe. Dobiveni rezultati (Tablica 3) ukazuju na nepostojanje statistički značajne razlike u preferenciji narodne glazbe između učenika i učenica. Rezultati nisu u skla$\mathrm{du}$ s postavljenom hipotezom $(\mathrm{t}(155)=0.04, \mathrm{p}>0.05)$.

Istraživanja o utjecaju spola na glazbene preferencije pokazuju kako žene generalno imaju pozitivnije stavove prema glazbi u odnosu na muškarce (Crowther i Durkin, 1982), dok LeBlanc (1982) ističe kako spol slušatelja ima izuzetno veliki utjecaj na formiranje njegovih glazbenih preferencija. Rezultati dobiveni u našem istraživanju nisu u skladu s rezultatima Hargreaves, Comber i Colley (1995) koji su istraživali glazbene preferencije učenika između 11 i 16 godina. Njihovi rezultati pokazuju da učenice preferiraju raznolikije glazbene stilove u odnosu na učenike, kako učenici više preferiraju heavy metal i rock glazbu, a učenice reggae, pop, jazz, umjetničku i narodnu glazbu.

Rezultati istraživanja Dobrote i Reić Ercegovac (2009) upućuju na to da spol značajno utječe na poznatost glazbi svijeta i umjetničke glazbe i to na način da oba glazbena stila bolje poznaju učenice.

Tablica 3. Razlike u preferenciji narodne glazbe s obzirom na spol

\begin{tabular}{|l|c|c|c|c|c|c|}
\hline \multicolumn{1}{|c|}{ Spol } & N & M & Sd & t & df & p \\
\cline { 1 - 4 } Učenici & 68 & 3.57 & 0.72 & \multirow{2}{*}{0.04} & \multirow{2}{*}{155} & \multirow{2}{*}{0.87} \\
\cline { 1 - 4 } Učenice & 89 & 3.56 & 0.71 & & & \\
\hline
\end{tabular}

$\mathrm{p}<0.05$

H2: Učenici osmih razreda u odnosu na učenike četvrtih razreda u većoj mjeri preferiraju narodnu glazbu.

Kako bismo provjerili drugu hipotezu izračunat je t-test. Dobiveni rezultati (Tablica 4) pokazuju da ne postoji statistički značajna razlika između učenika četvrtih i osmih razreda s obzirom na preferenciju narodne glazbe. Stoga dobiveni rezultati nisu u skladu s postavljenom hipotezom pa zaključujemo kako učenici osmih razreda, u odnosu na učenike četvrtih razreda, ne pokazuju veće preferencije narodne glazbe $(\mathrm{t}(155)=1.38, \mathrm{p}>0.05)$. 
Iako smo pretpostavili da će učenici osmih razreda u većoj mjeri preferirati narodnu glazbu u odnosu na učenike četvrtih razreda, pokazalo se da ni u ovom slučaju ne postoji statistički značajna razlika. Pokušavajući utvrditi utjecaj dobi na formiranje glazbenih preferencija Hargreaves koristi pojam otvorenost (eng. open-earendess) koji govori o tome da mlađa djeca pokazuju veće preferencije nekonvencionalnih i neobičnih glazbenih stilova (avangardna, aleatorička, elektronska glazba), s obzirom da »pokazuju manje dokaza o akulturaciji normativnim standardima 'dobrog ukusa' u odnosu na stariju djecu« (Hargreaves, 1982, 51).

LeBlanc operacionalizira pojam otvorenost kao toleranciju slušatelja prema različitim glazbenim stilovima, a o utjecaju dobi na glazbene preferencije govori na sljedeći način: (1) mlađa djeca otvorenija su prema nepoznatoj glazbi u odnosu na stariju djecu; (2) otvorenost se smanjuje s ulaskom u adolescenciju; (3) na prelasku iz adolescencije u zrelo doba dolazi do djelomičnog preokreta otvorenosti; (4) otvorenost se smanjuje s ulaskom u starije doba (LeBlanc, 1982, 2). Opadanje otvorenosti do kojega dolazi u kasnom djetinjstvu javlja se u dobi između deset $i$ jedanaest godina i manifestira se snažnim preferencijama popularne glazbe i podjednako snažnom generalnom nesklonošću prema svim drugim glazbenim stilovima.

Tablica 4. Razlike u preferenciji narodne glazbe s obzirom na dob

\begin{tabular}{|l|c|c|c|c|c|c|}
\hline \multicolumn{1}{|c|}{ Razred } & N & M & Sd & t & df & p \\
\hline 4. razred & 80 & 3.64 & 0.70 & \multirow{2}{*}{1.38} & \multirow{2}{*}{155} & 0.81 \\
\hline 8. razred & 77 & 3.48 & 0.72 & & & \\
\hline
\end{tabular}
$\mathrm{p}<0.05$

H3: Učenici više preferiraju narodnu glazbu s područja Dalmacije u odnosu na narodnu glazbu iz drugih dijelova Hrvatske.

Kako bismo ispitali postoji li statistički značajna razlika u preferenciji narodne glazbe s područja Dalmacije u odnosu na narodnu glazbu iz drugih dijelova Hrvatske, izračunat je t-test. Dobiveni rezultati (Tablica 5) pokazuju da postoji statistički značajna razlika između preferencija narodne glazbe iz Dalmacije i ostalih regija Hrvatske i to na način da učenici više preferiraju narodnu glazbu Dalmacije $(\mathrm{t}(156)=19.47$, $\mathrm{p}<0.05$ ). 
Dobivene rezultate moguće je objasniti pretpostavkom da sudionici češće slušaju narodnu glazbu s područja Dalmacije nego iz drugih dijelova Hrvatske pa im je, slijedom toga, takva glazba poznatija. I rezultati drugih istraživanja (Shehan, 1985; Carper, 2001) pokazuju kako učenici preferiraju poznatu glazbu (Dobrota i Reić Ercegovac, 2009). Shehan (1979) ističe kako ponovljeno izlaganje glazbi povećava njeno poznavanje, što rezultira boljim razumijevanjem glazbe a time i većim glazbenim preferencijama.

Tablica 5. Razlike u preferenciji narodne glazbe s područja Dalmacije u odnosu na glazbu iz ostalih dijelova Hrvatske

\begin{tabular}{|l|c|c|c|c|c|c|}
\hline $\begin{array}{c}\text { Područje iz kojega } \\
\text { potječe glazba }\end{array}$ & N & M & Sd & t & df & p \\
\cline { 1 - 5 } Dalmacija & \multirow{2}{*}{157} & 4.06 & 0.77 & \multirow{2}{*}{19.47} & 156 & 0.00 \\
\cline { 1 - 3 } Ostale regije Hrvatske & 3.06 & 0.79 & & \\
\hline
\end{tabular}
$\mathrm{p}<0.05$

H4: Učenici više preferiraju vokalnu i vokalno-instrumentalnu narodnu glazbu u odnosu na instrumentalnu narodnu glazbu.

Sudionici općenito više preferiraju vokalnu i vokalno-instrumentalnu narodnu glazbu u odnosu na instrumentalnu narodnu glazbu, što potvrđuju i rezultati t-testa (Tablica 6). Dakle, dobiveni rezultati pokazuju da postoji statistički značajna razlika u preferenciji narodne glazbe prema izvođačima te glazbe. Učenici općenito, neovisno o dobi i spolu, u većoj mjeri preferiraju vokalnu i vokalno-instrumentalnu narodnu glazbu u odnosu na instrumentalnu glazbu $(\mathrm{t}(156)=7.67, \mathrm{p}<0.05)$.

Dobiveni rezultati dijelom su u skladu s rezultatima LeBlanca (1981), koji je ispitivao utjecaj izvođača na glazbene preferencije učenika petih razreda osnovne škole. Glazbeni upitnik bio je koncipiran od 24 glazbena ulomka koja su pripadala različitim glazbenim stilovima. Sudionici preferiraju instrumentalnu glazbu u odnosu na vokalnu, ali samo u slučaju glazbenih ulomaka koji pripadaju umjetničkoj glazbi. U slučaju rock/pop i jazz glazbe, sudionici iskazuju veće preferencije vokalne glazbe.

Istražujući glazbene preferencije učenika petih i šestih razreda osnovne škole prema jazz glazbi, LeBlanc i Cote (1983) uočavaju kako učenici preferiraju instrumentalne ulomke u odnosu na vokalne te kako učenice preferiraju ženske pjevače, a učenici muške. 
Tablica 6. Razlike u preferenciji vokalne i vokalno-instrumentalne glazbe u odnosu na instrumentalnu glazbu

\begin{tabular}{|l|c|c|c|c|c|c|}
\hline $\begin{array}{c}\text { Vrsta glazbe prema } \\
\text { izvodačima }\end{array}$ & N & M & Sd & t & df & p \\
\hline $\begin{array}{l}\text { Vokalna i } \\
\text { vokalno-instrumentalna }\end{array}$ & \multirow{2}{*}{157} & 3.80 & 0.84 & 7.67 & 156 & 0.00 \\
\cline { 1 - 5 } Instrumentalna & 3.33 & 0.78 & & & \\
\hline
\end{tabular}

$\mathrm{p}<0.05$

\section{Zaključak}

Ovim istraživanjem pokušale su se ispitati preferencije narodne glazbe učenika četvrtih i osmih razreda osnovne škole. Rezultati ukazuju na nepostojanje statistički značajne razlike u preferenciji narodne glazbe s obzirom na spol i dob, ali su uočene razlike glazbenih preferencija s obzirom na geografski lokalitet iz kojega glazba potječe te $\mathrm{s}$ obzirom na izvođače narodne glazbe.

Budući da se glazbene preferencije pojedinca nalaze pod utjecajem niza različitih faktora, poput glazbeno-izražajnih sastavnica (Teo, 2005; Dobrota i Reić Ercegovac, 2014) i socio-demografskih varijabli (Dobrota i Reić Ercegovac, 2009; Teo, 2005), u budućim istraživanjima mogle bi se istražiti preferencije narodne glazbe s obzirom na različite glazbeno-izražajne sastavnice, poput tempa, tonaliteta ili ugođaja te $\mathrm{s}$ obzirom na neke socio-demografske varijable.

Nadalje, moguće je proširiti uzorak na učenike gimnazija i učenike strukovnih škola kako bi se istražio utjecaj dobi te formalnih i neformalnih utjecaja na formiranje njihovih glazbenih preferencija. Rezultati istraživanja pokazuju kako vrsta škole utječe na preferencije glazbi svijeta i umjetničke glazbe na način da gimnazijalci pokazuju značajno veće preferencije oba glazbena stila (Dobrota i Reić Ercegovac, 2009).

Krajnji cilj glazbene nastave je proširivanje glazbenog ukusa učenika stoga bi glazbeni pedagog trebao okružiti djecu kvalitetnom i raznolikom glazbom. Među takvim glazbenim iskustvima važno mjesto zasigurno pripada i narodnoj glazbi kraja iz kojega dijete potječe, ali i glazbi iz drugih krajeva svijeta. Budući da rezultati ovog istraživanja ukazuju na to da učenici preferiraju glazbu regije iz koje potječu, u ovom slučaju dalmatinsku narodnu glazbu, tijekom glazbene nastave bilo bi ih uputno upoznati s glazbenom baštinom ostalih regija Hrvatske 
i svijeta kako bismo proširili njihov glazbeni ukus i razvijali toleranciju prema novim i nepoznatim kulturama. Kulturne interakcije koje se događaju u suvremenom svijetu stvaraju veliko bogatstvo i raznolikost glazbenih formi i iskustava, a glazbena nastava koja prihvaća, reflektira i obogaćuje takvu raznolikost od neprocjenjive je vrijednosti za glazbeni razvoj svakog učenika.

\section{Literatura}

Carper, Kenneth (2001), »The effects of repeated exposure and instructional activities on the least preferred of four culturally diverse musical styles with kindergarten and pre-k children «, Bulletin of the Council for Research in Music Education, 151, str. 41-50.

Colley, Ann (2008), »Young people's musical taste: Relationship with gender and gender-related traits«, Journal of Applied Social Psychology, 38(8), str. 2039-2055. http://dx.doi.org/10.1111/j.1559-1816.2008.00379.x

Crowther, Edward R. i Durkin, Kevin (1982), »Sex- and age-related differences in the musical behavior, interests, and attitudes towards music of 232 secondary school students«, Educational Studies, 8(2), str. 131-139.

Dobrota, Snježana (2012), Uvod u suvremenu glazbenu pedagogiju, Split: Filozofski fakultet u Splitu.

Dobrota, Snježana i Reić Ercegovac, Ina (2009), »Glazbene preferencije mladih s obzirom na neke sociodemografske varijable«, Odgojne znanosti, 11(2), str. 381-398.

Dobrota, Snježana i Reić Ercegovac, Ina (2014), „Student's musical preferences: The role of music education, characteristics of music and personality traits«, Croatian Journal of Education, 16(2), str. 363-384.

Flowers, Patricia J. (1988), »The effect of teaching and learning experiences, tempo, and mode on undergraduates' and children's music preference«, Journal of Research in Music Education, 36(1), str. 19-34. http://dx.doi. org/10.2307/3345011

Hargreaves, David J. (1982), »The development of aesthetic reactions to music«, Psychology of Music (Special issue), str. 51-54.

Hargreaves, David J.; Comber, Chris i Colley, Ann (1995), »Effects of age, gender, and training on musical preferences of British secondary school students«, Journal of Research in Music Education, 43(3), str. 242-250. http://dx.doi. org $/ 10.2307 \% 2 \mathrm{~F} 3345639$ 
Hargreaves, David J., Miell, Dorothy E. i MacDonald, Raymond A. (2005), »How do people communicate using music?«, u: Miell, Dorothy E.; MacDonald, Raymond A. i Hargreaves, David J. (ur.), Musical Communication, Oxford: Oxford University Press, str. 1-25. http://dx.doi.org/10.1093/acprof:oso/978 0198529361.003.0001

Juslin, Patrik N. i Laukka, Petri (2004), »Expression, perception, and induction of musical emotions: A review and a questionnaire study of everyday listening«, Journal of New Music Research, 33(3), str. 217-238.

LeBlanc, Albert (1981), »Effects of style, tempo, and performing medium on children's music preference«, Journal of Research in Music Education, 29(2), str. 143-156. http://dx.doi.org/10.2307/3345023

LeBlanc, Albert (1982), »An interactive theory of music preference«, Journal of Music Therapy, 19(1), str. 28-45. http://dx.doi.org/10.1093/jmt/19.1.28

LeBlanc, Albert i Cote, Richard (1983), »Effects of tempo and performing medium on children's music preference«, Journal of Research in Music Education, 31(1), str. 57-66. http://dx.doi.org/10.2307/3345110

LeBlanc, Albert i McCrary, Jan (1983), »Effects of tempo on children's music preference «, Journal of Research in Music Education, 31(4), str. 283-294. http://dx.doi.org/10.2307/3344631

Montgomery, Amanda P. (1996),»Effect of tempo on music preferences of children in elementary and middle school«, Journal of Research in Music Education, 44(2), str. 134-146. http://dx.doi.org/10.2307/3345666

North, Adrian C. i Hargreaves, David J. (2008), The Social and Applied Psychology of Music, New York: Oxford University Press. http://dx.doi.org/10.1093/ acprof:oso/9780198567424.001.0001

Schäfer, Thomas (2008), Determinants of Music Preferences (doctoral thesis), Chemnitz: Chemnitz University of Technology.

Schwartz, Kelly D. i Fouts, Gregory T. (2003), »Music preferences, personality style, and developmental issues of adolescents«, Journal of Youth and Adolescence, 32(3), str. 205-213. http://dx.doi.org/10.1023/A:1022547520656

Shehan, Patricia K. (1979), »The effect of the television series music on music listening preferences and achievement of elementary general music students«, Contributions to Music Education, 7, str. 51-62.

Shehan, Patricia K. (1985), »Transfer of preference from taught to untaught pieces of non-Western music genres", Journal of Research in Music Education, 33(3), str. 149-158. http://dx.doi.org/10.2307/3344802

Teo, Timothy (2005), »Relationship of selected listener varibales and musical preference of young student in Singapore«, Music Education Research, 7(3), str. 349-362. http://dx.doi.org/10.1080/14613800500324556 


\section{PUPILS' MUSICAL PREFERENCES TOWARDS FOLK MUSIC}

\section{Snježana Dobrota, Matea Maslov}

This paper examines the musical preferences of students in the fourth and eighth classes of elementary school towards folk music. Four variables were selected, and their influence on preferences towards folk music were examined. The research framework applied a general data survey and an evaluation scale to examine preferences towards musical selections on a sample of 157 pupils in the fourth and eighth year of elementary school. The results confirm that there is no statistically significant difference in the preference of male and female pupils towards folk music, nor is there a difference in preference towards folk music between fourth and eighth year pupils. The results also show that pupils generally prefer vocal and vocal-instrumental folk music to instrumental folk music, and that they generally prefer folk music from Dalmatia as opposed to folk music from other parts of Croatia.

Key words: musical preference, folk music, music teaching 


\section{Prilog 1.}

Draga učenice/učeniče!

Pred tobom se nalazi anketni upitnik kojim ispitujemo tvoj stav prema narodnoj glazbi. Molim te da iskreno odgovoriš na postavljena pitanja. Ispitivanje je anonimno, a prikupljeni podatci koristit će se isključivo u istraživačke svrhe i neće se zlorabiti na bilo koji način.

Zahvaljujem ti na suradnji!

1. Zaokruži kojeg si spola:
a) Muško
b) Žensko

2. Koji razred pohađaš?
a) 4. razred
b) 8. razred

3. Plešeš li ili sviraš instrument u nekom kulturno-umjetničkom društvu? (folklor)

a) $\mathrm{Da}$

b) $\mathrm{Ne}$

4. Pjevaš li ili si nekad pjevao/pjevala u klapi?
a) $\mathrm{Da}$
b) $\mathrm{Ne}$

5. Jesi li ikada prisustvovao/prisustvovala folklornom nastupu ili koncertu klapa?

a) $\mathrm{Da}$

b) $\mathrm{Ne}$

6. Poslušaj glazbene primjere. Ocijeni sljedeće glazbene odlomke zaokruživanjem odgovarajuće brojke. Brojke znače: $1=$ uopće mi se ne sviđa; 2 = ne sviđa mi se; 3 = osrednje mi se sviđa; 4 = sviđa mi se; 5 = jako mi se sviđa. 


\begin{tabular}{|c|lllll|}
\hline Glazbeni primjer & \multicolumn{6}{|c|}{ Ocjene } \\
\hline 1 & 1 & 2 & 3 & 4 & 5 \\
\hline 2 & 1 & 2 & 3 & 4 & 5 \\
\hline 3 & 1 & 2 & 3 & 4 & 5 \\
\hline 4 & 1 & 2 & 3 & 4 & 5 \\
\hline 5 & 1 & 2 & 3 & 4 & 5 \\
\hline 6 & 1 & 2 & 3 & 4 & 5 \\
\hline 7 & 1 & 2 & 3 & 4 & 5 \\
\hline 8 & 1 & 2 & 3 & 4 & 5 \\
\hline 9 & 1 & 2 & 3 & 4 & 5 \\
\hline 10 & 1 & 2 & 3 & 4 & 5 \\
\hline
\end{tabular}

